\title{
Evaluation of an individualised programme to promote self-care in sleep-activity in patients with coronary artery disease - a randomised intervention study
}

Anna Johansson, Anita Adamson, Jan Ejdeback and Ulla Edéll-Gustafsson

\author{
Linköping University Post Print
}

\section{Tweet}

N.B.: When citing this work, cite the original article.

Original Publication:

Anna Johansson, Anita Adamson, Jan Ejdeback and Ulla Edéll-Gustafsson, Evaluation of an individualised programme to promote self-care in sleep-activity in patients with coronary artery disease - a randomised intervention study, 2014, Journal of Clinical Nursing, (23), 19-20, 28222834.

http://dx.doi.org/10.1111/jocn.12546

Copyright: Wiley: 12 months

http://eu.wiley.com/WileyCDA/

Postprint available at: Linköping University Electronic Press

http://urn.kb.se/resolve?urn=urn:nbn:se:liu:diva-112484 


\title{
Evaluation of an individualised programme to promote self-care in sleep- activity in patients with coronary artery disease - a randomised intervention study
}

\author{
Anna Johansson, ${ }^{1,2}$ Anita Adamson, ${ }^{3}$ Jan Ejdebäck ${ }^{1} \&$ Ulla Edéll-Gustafsson ${ }^{4}$
}

${ }^{1}$ Department of Cardiology, Skaraborgs hospital, Skövde, Sweden, ${ }^{2}$ Department of Health Care Sciences, School of Life Sciences, University of Skövde, Sweden, ${ }^{3}$ Department of Physical therapy, Skaraborgs hospital, Skövde, Sweden, ${ }^{4}$ Department of Medical and Health Sciences, University of Linköping, Sweden

Running Head: Promote self-care in sleep-activity

Authors: Anna Johansson, RN, PhD and Clinical Lecturer, Department of Cardiology, Skaraborg hospital, Skövde and Department of Health Care Sciences, School of Life Sciences, University of Skövde, Sweden. Anita Adamson, MSc, Reg OT, Physiotherapist, Department of Physical therapy, Skaraborg hospital, Skövde, Sweden. Jan Ejdebäck, PhD, Medical Doctor, Department of Cardiology, Skaraborg hospital, Skövde, Sweden. Ulla EdéllGustafsson, PhD, CCRN, Professor and Senior Lecturer, Department of Medical and Health Sciences, University of Linköping, Sweden.

\section{Acknowledgements}

The authors wish to thank the RN Lis Ståhl and RN Lena Landenmark from the Department of Cardiology at Skaraborgs hospital in Skövde, Sweden for assistance with patient recruitment and education. This study was supported by grants from the Research fund at Skaraborg Hospital, Sweden (VGSKAS-9122) and from the Skaraborg Institute, Sweden (register No .07/1036).

$\begin{array}{ll}\text { Correspondence: } & \text { Anna Johansson } \\ & \text { RN, Clinical lecturer, } \mathrm{PhD} \\ & \text { Department of Cardiology, unit } 32 \\ & \text { Skaraborgs hospital, Skövde } \\ & \text { SE-541 85 Skövde } \\ & \text { Telephone: +46 500431248 } \\ \text { e-mail: anna.m.johansson@ vgregion.se }\end{array}$




\section{Abstract}

Aims and objective. To evaluate the effectiveness of an individualised programme to promote self-care in sleep-activity in patients with coronary artery disease.

Background. Recent scientific findings have shown that low physical exercise and stress interfere with coronary artery disease patients' sleep quality and sleep efficiency independent of gender, age and co-morbidity.

Design. A randomised pretest- posttest control design.

Methods. Forty-seven patients who had undergone a coronary revascularization procedure and/or pharmacological treatment three to seven weeks earlier at a general hospital were randomised to either an intervention group or a control group. Data collection by questionnaires, a study-specific sleep diary and actigraphy registration for 10 consecutive 24hour periods, with a follow-up after three to four months. The intervention group underwent a nurse-led individualised education programme to promote self-care of sleep-activity. Sleep habits and sleep-related lifestyle together formed the basis for setting up individual goals together with the nurse. Individual advice on physical training, relaxation exercise and a CDbased relaxation programme were provided by a physiotherapist. Both groups received a brochure about sleep and stress.

Results. At a three- to four-month follow-up the main improvements were seen in the intervention group regarding sleep quality, sleep duration and sleep efficiency in the sleep diary and sleep efficiency in actigraphy. Statistical improvements in health-related quality of life were revealed. This was not so obvious in the control group.

Conclusions. An individualised intervention programme to promote self-care of sleep-activity including relaxation in patients with coronary artery disease led by a nurse may improve sleep 
quality. However, a longitudinal study to promote self-care in sleep-activity should be performed using a larger sample and multiple sites with continuous follow-ups to determine whether any positive effects remain stable over time.

\section{Relevance to clinical practice}

Implementation of a multi-professional individualised programme to promote self-care of sleep-activity including relaxation based on patients’ needs, supported by a health-care team and led by nurses is important in clinical practice.

Key words: actigraphy, control group, coronary artery disease, health, nursing, pretestposttest design, self-care, sleep-activity, sleep diary 


\section{INTRODUCTION}

Coronary artery disease (CAD) is a largely preventable worldwide disease and it is important to continue supporting a systematic approach to cardiovascular risk reduction through teambased, nurse-directed management (Berra et al. 2011). Patients with CAD often suffer from emotional, cognitive and social disturbances and experience reduced health-related quality of life (HRQoL), which over time, result in failure to adopt a healthy lifestyle. It has been shown that short sleepers (Cappuccio et al. 2011), especially those with poor sleep quality (Hoevenaar-Blom et al. 2011), have an increased risk of cardiovascular disease. Compared to the general population, poor sleep quality is common in patients with CAD (Johansson et al. 2011). Total nocturnal sleep duration is an important determinant factor for recovery and waking functionality (Jay et al. 2007).

\section{BACKGROUND}

Circadian rhythms (biological clock), regulated by the suprachiasmatic nucleus (SCN), control our wakefulness and alertness (sleep-wake cycle) and how several bodily functions (e.g. motor activity, eating and body temperature) recur in a cycle of about 24 hours. SCN, the site of the endogenous circadian pacemaker, is normally synchronized with the environment, e.g. daylight (Czeisler et al. 2011). Sleep is also regulated by a homeostatic process, which is dependent on the amount of prior sleep and wakefulness. Research findings suggest that sleep is an important homeostatic regulator of factors contributing to the development of the metabolic syndrome and of cardiovascular disease (Miller \& Cappuccio 2007, Mullington et al. 2009). Furthermore, risk factors may have additive and interactive effects influencing cardiac prognosis adversely (Spindler \& Pedersen 2005). Recent scientific findings show that low physical exercise and stress interferes with CAD patients’ sleep quality and sleep efficiency (SE\%) independent of gender, age and co-morbidity (Johansson et al. 2011). 
Study results indicate that the use of profiling coronary artery bypass surgery (CABG) patients on their symptoms prior to hospital discharge may assist health care providers to identify patients who could be at risk for having more difficulty with physical functioning and physical activity during the first 6 months after surgery (Zimmerman et al. 2010). Symptoms of pain, fatigue and sleep disturbances are commonly reported in patients after a myocardial infarction (Brink et al. 2012) and post-CABG (Zimmerman et al. 2010), and may promote the development of sleeplessness behavior (Edéll-Gustafsson et al. 2006) with experiences of poor efficacy for self-care in sleep (Johansson et al. 2007, Brink et al. 2012). Self-care according to Orem (2001) is an active phenomenon performed each day that is initiated voluntarily and intentionally by an individual in concrete life situations after decision-making skills to choose an appropriate course of action. The process of self-care is considered essential to be used to develop tailored interventions that improve outcome for patients in the management of their chronic illness (Riegel et al. 2012).

Sleep quality is a complex phenomenon that is difficult to define and measure objectively (Buysse et al. 1989). However, it is important to understand the subjective meaning of sleep quality (Harvey et al. 2008). Perceiving a higher sleep quality would more likely influence well-being and cognitive functions by positively affecting psychosocial and physical functioning (LeBlanc et al. 2007, Harvey et al. 2008, Ustinov et al. 2010). Self-perceived poor sleep quality may have a synergistic effect on short sleep duration and coronary heart disease (CHD). Furthermore, sleep quality is an important factor in the physiological recovery of the body also during sleep, and good sleep quality may prevent CHD (Hoevenaar-Blom et al. 2011).

Combined with questionnaires for retrospective self-assessed sleep quality and healthrelated quality of life (HRQoL), night-to-night variability in sleep-wake patterns can be detected by using a sleep diary combined with actigraphy (Vallièrs \& Morin 2003, Ancoli- 
Israel et al. 2003). Actigraphy can with advantage be used for registration during longer periods in the home environment (Van de Water et al. 2011). From a more holistic perspective, it is also important to describe the patients' own experiences of their sleep (Johansson et al. 2007, Harvey et al. 2008, Ustinov et al. 2010). Patients’ capability, capacity and skills to perform various tasks as well as cognitive and creative activities to improve patients' sleep quality in various degrees have been described by Johansson et al. (2007).

To achieve effectiveness and efficiency, a self-care programme should contain information on how to manage symptoms and change behavior and lifestyle (AHA 2010). CAD is a chronic illness requiring continuous adaptation to healthy behavior (Pörn 1993).

Research has documented that nurse-directed case management improves cardiovascular risk factors, lifestyle, and outcomes (Berra et al. 2011). However, no studies have been found as to whether intervention by means of an individual sleep education programme combined with a relaxation programme improves CAD patients’ sleep-activity.

\section{AIM}

The aim of this randomised intervention study was to evaluate the effectiveness of an individualised programme to promote self-care in sleep-activity in patients with CAD following treatment.

Our hypothesis was that an individualised intervention programme may promote self-care in sleep-activity in patients with CAD.

\section{METHODS}

\section{Design}


A randomized pretest- posttest control design was used (Moher et al. 2010, Polit \& Beck 2008). In addition, a comparative design was used between groups. Sample size was calculated for the sleep variables SE\% $(r=-0.44)$ and for sleep onset latency $(r=0.45)$ (Uppsala Sleep Inventory) which showed a need for a sample size between 32 to 50 participants in each group for power =.80. (Polit \& Beck 2008).

\section{Participants}

Between February 2009 and February 2011, 53 patients who had undergone percutaneous coronary intervention (PCI), coronary artery bypass surgery (CABG) and/or pharmacological treatment 3 to 7 weeks earlier at a general hospital in southwest Sweden, were randomised to either an intervention group (I-group), where they received education in an individual nonpharmacological programme to promote self-care in sleep and activity and a CD-based relaxation programme with a follow-up after 3-4 months, or a control group (C-group) with no such interventions. Exclusion criteria were patients' inability to read and understand the Swedish language, verified diseases with poor prognoses such as a malignant disease, a history of cerebrovascular disease, neurologic disease with sequelae or mental disorder under medical treatment or alcoholic and/or drug abuse. The flowchart of the progress through the trial phases is shown in Figure 1. There were 47 eligible patients for the analysis, of which 24 patients in the intervention group and 23 patients in the control group.

- Please insert Figure 1 about here-

\section{Interventions}

At a routine care nurse follow-up appointment at the clinic 3-7 weeks after PCI, CABG and/or pharmacological treatments an initial screening was performed. The patients who reported 
problems with too little sleep (yes) and poor sleep quality (score $\geq 4=$ rather bad to bad) on the Uppsala Sleep Inventory (USI) were included. These patients received verbal and written information about the study, questionnaires, an invitation to participate and a pre-addressed envelope to be returned within seven days. They were randomised consecutively after giving informed written consent to participate in the study. A sealed envelope was drawn from a box in the department stating whether the patient would belong to the intervention group (I-group) or the control group (C-group). Both groups received medical care and check-ups according to standard treatment by a cardiologist who was blinded to group allocation.

The study flow of an individualised programme to promote self-care in sleep-activity is shown in Figure 2. The I-group filled in the questionnaires about sleep and daytime sleepiness (M1). Thereafter they performed actigraphy registration and kept a sleep diary for 10 consecutive 24-hour periods (M2). This was followed by a nurse-led individualised education programme to promote self-care of sleep-activity (X1). At the same time, individual advice on physical training, relaxation exercise and a CD-based relaxation programme were provided by a physiotherapist (X1). The patients were recommended to perform their exercises every day. The recommended levels of physical activities was go on for $>30$ minutes at moderate intensity, for example a fast walk, thus following general health promotion recommendations regarding physical activity (Jansson \& Anderssen 2008).

The education programme included an individual sleep analysis related to circadian rhythm and activities. The appropriate sleep problems were partly based on the baseline data (actigraphy analysis, sleep diary) and the patients’ perceived sleep and activity. Sleep habits and sleep-related lifestyle together formed the basis for setting up individual goals together with the nurse. The sleep hygiene education intended to teach individuals about the impact of lifestyle habits such as diet, exercise and drug use in addition to the influence of environmental factors. The advice on sleep hygiene included reducing disturbing factors in 
the bedroom such as temperature, noise and lights. The education programme took place on a single occasion and the duration depended on the needs of individual patients. The patients received a brochure (Thernfrid 2003) about sleep and stress, and were given a CD-based relaxation programme and instructions by a physiotherapist. The sleep brochure contained general information about sleep as a basic need, causes and effects of sleep deprivation, stress as a sleep disturbing factor and how to manage it, and sleep hygiene - general advice for better sleep and where to turn for further advice. All patients were offered telephone support by a nurse throughout the study. No documentation was done in the patients' case report form at the time of the telephone call. A follow-up (M3) was performed 3-4 months after the education programme (X1) using actigraphy, sleep diary for 10 consecutive 24-hour periods and questionnaires. It also included a self-reported evaluation of the individualised setting of goal/goals.

The C-group answered the same questionnaires as the I-group (M1), performed actigraphy registration and filled in a sleep diary for 10 consecutive 24-hour periods (M2). They received the same brochure about sleep as the I-group (X2). No individual education programme, physical training advice or CD-based relaxation programme was given to the C-group. A second evaluation with the same questionnaires, actigraphy registration and diary was performed 3-4 months after the sleep brochure was sent to the participants (M3).

The responsible nurse conducted the individual specific education programme, whereas the same physiotherapist provided all instructions and physical training. The physiotherapist did not take part in the nurse’s individual specific education programme.

Before commencing this study to ensure the reliability of the measure, the staff went on a 3day education and training sleep programme. The sleep programme was based on Borbély's model (Borbély 1987, 1994) and part of Morin and Espie's clinical guide to assess and treat 
insomnia (Morin \& Espie 2004). Sleep education elements, literature studies and clinical practice training were included. They also read a booklet on "How to sleep better” (Dyregrov 2006). Thereafter the design was tested on one patient through actigraphy recordings and a sleep diary for a 10 consecutive 24-hour periods, respectively. These were evaluated and discussed among the staff. The programme was led and followed-up by two members of the research group (AJ, U E-G). After evaluation, a few minor changes were implemented and a relaxation programme was developed and tested on an equivalent patient group (AA).

-Please insert Figure 2 about here-

\section{Data collection}

The methods were questionnaires, sleep diary, actigraphy recordings and an individual patient education programme for sleep, physical activity and relaxation.

\section{Questionnaires}

The Uppsala Sleep Inventory (USI) was used for assessing perceived sleep during the last four weeks (Hetta et al. 1985, Edéll-Gustafsson et al. 2006). Sleep variables were: Sleep quality defined as “how have you slept the past 4 weeks”, assessed on a 5-grade scale, from good (score 1) to bad (score 5), sleep onset latency (SOL) in minutes, sleep duration (hour and minutes), daytime napping (frequency), nocturnal awakenings (frequency) and sleep efficiency. Sleep efficiency was calculated as the ratio of reported nocturnal sleep duration and time spent in bed multiplied by 100 (SE\%). An SE\% of 85\% or higher was considered to be satisfactory (Morin and Espie 2004). The severity of sleep problems and daytime symptoms such as difficulty falling asleep, maintaining sleep, early morning awakening and inability to be refreshed by sleep, daytime sleepiness and physical and mental tiredness were 
scored on a 5-point scale from no problems (1) to very major problems (5). The questions concerning sleep duration, the degree of sleep problems and daytime symptoms formed the basis for the operational definition of insomnia. The definitions of insomnia and nonrestorative insomniacs have been described by Buysse et al. (2006) and Morin et al. (2006). Socio-demography, self-reported diagnoses and pharmacologic therapy were also assessed by the USI (Table 1). Part of the USI has been validated (Hetta et al. 1998, Edéll-Gustafsson 2002) and tested for internal consistency by Cronbach’s alpha (Johansson et al. 2011) and was satisfactory. In this study, Cronbach's alpha for the USI scale was 0.76 at baseline and 0.87 at follow-up for items coding at similar direction.

The Epworth Sleepiness Scale (ESS) was used for assessment of excessive daytime sleepiness due to the likelihood of falling asleep (rated on a 4-point scale of 0 [never] to 3 [high chance]) while engaged in eight passive or active waking activities. A summated score of 10 or higher was considered to indicate excessive daytime sleepiness (Johns 1991).The scale has been well validated and reliability tested (Johns \& Hocking 1997, Beiske et al. 2009). Cronbach's alpha for the scale in this study was 0.78 at baseline and 0.81 at follow-up.

The Medical Outcomes Study Short Form Health Survey (SF-36) was used to measure health-related quality of life (HRQoL). The questionnaire consists of eight health domains; physical functioning (Pf), role-physical (Rp), bodily pain (Bp), general health (Gh), vitality (Vt), social functioning (Sf), role-emotional (Re) and mental health (Mh). The questions relate to the last four weeks and each domain scores 0-100, where a higher score indicates better HRQoL. The eight domains are summarized in two overall health indexes; physical (PCS) and mental (MCS) component summary (Sullivan et al. 2002). Dempster and Donnelly (2000) have shown that SF-36 has high internal consistency coefficients and good discriminative validity among individuals with ischemic heart disease. Cronbach's alpha for the scale in this study was 0.74 at baseline and 0.83 at follow-up. 
Sleep diary

The study-specific sleep diary contained questions concerning the participants' current sleep day by day for 10 days, thus providing an overview of the participants' sleep pattern.

Descriptions of measured sleep diary variables are shown in Table 2. The current sleep data was used for controlling the concordance to the actigraphy registrations. The study-specific sleep diary was created with support from the literature (Edéll-Gustafsson 1999, Morin \& Espie 2004) and the authors' own experience from clinical work among patients with heart disease.The participants were informed to fill in the sleep diary in the morning and in the evening. Part of the sleep diary has been validated against polysomnography (EdéllGustafsson 1999) and the Uppsala Sleep Inventory (Hetta et al.1998, Edéll-Gustafsson 1999). Sleep duration, sleep latency, sleep onset and nocturnal awakenings were in congruence with polysomnography recorded sleep (Edéll-Gustafsson 1999). In addition, the sleep diary included three questions about physical performance: I. During the day, did you perform any physical activity such as biking/walking for less than 30 minutes (1), more than 30 minutes (2) or not at all (3), II. To what degree did you feel hot/strained during your physical activity today not at all (1), to some extent (2), fairly much (3) and very much (4). III. To what extent did you experience anxiety/fear in connection with your physical activity today not at all (1), to some extent (2), fairly much (3) and very much (4). Another question in the sleep diary was "Have the CD-based relaxation programme improved your sleep” Not at all (1), to some extent (2), fairly much (3) and very much (4).

\section{Actigraphy recordings}

Rest-activity patterns including indirect sleep were measured during ten consecutive 24-hour periods, using Cambridge Actiwatch with a light recorder (the Model Actiwatch-L (AW-L), Cambridge Neurotechnology Ltd, UK (2001), a small device similar to a wristwatch placed 
on the non-dominant wrist. Thereafter, data was transferred to the Actiwatch computer program and analyzed by the software program Actiwatch Sleep Analysis, version 1.09 (2001). Visual graphs of the sleep-wake cycles were provided by the program. These were used to motivate and educate the patients when providing them with sleep hygiene advice. Information about time going to bed and getting out of bed provided by the patients's sleep diaries was used to edit and calculate the actigraphy data. To validate the recording time against actual time the actigraph was pre-programmed to start at 10 am for all participants. The patients wrote down the times and data for putting on and removing the actigraph from the wrist in the sleep diary. Periods of repetitive arm movements were scored as wakefulness and inactivity as sleep. Activity was measured by a piezo-electric accelerometer that was set up to record the integration of intensity, amount and duration of movement in all directions (Camntech Ltd. 2007). In the sleep diary, weekdays were compared with the corresponding weekday in the actigraphy recordings, respectively. Descriptions of measured actigraphy variables are shown in Table 2. Actigraphy recordings have been validated according to polysomnography in various populations and correspond reasonably well in comparison of total sleep time, number of nocturnal awakenings, wake time after sleep onset and sleep efficiency (SE\%) (Lichstein et al. 2006, Blackwell et al. 2008, Van de Water et al. 2011).

- Please insert Table 1 and Table 2 about here-

\section{Ethical considerations}

The study design was approved by the Regional Ethical Review Board. Principles according to the Helsinki declaration (WMA 2008) were followed. Informed and written consent was obtained from all participants in the study.

\section{Data analysis}


Absolute and relative frequencies, per cent, median (Q1-Q3), means (range), standard deviation (SD), response rate, and 95\% confidence interval (C.I.) were used for a general description of the results. The Chi-Square test and McNemar's test were used for assessment of categorical variables. For comparison between two independent groups the Mann-Whitney U test and Wilcoxon's test between within subjects were used. To explore associations between different variables Spearman's bivariate correlation was used. The variables ( $\mathrm{r}=$ z.35) were in the next step included in a multiple stepwise regression analysis to account for the variance of sleep quality outcome. Internal consistency was assessed using Cronbach's alpha. Internal dropouts occurred at a rate of $11 \%$. In this study, sample size was calculated for the sleep variables (USI) SE\% ( $r=-0.44)$ and for sleep onset latency $(r=0.45)$, which showed a need for a sample size between 32 to 50 in each group for power $=.80$ (Polit and Beck 2008). Statistical tests were two-tailed and alpha was set at $\mathrm{p}<0.05$. SPSS statistics 19.0 for Windows (SPSS Inc, Chicago, IL, USA) was used for all analysis (Field 2009).

\section{RESULTS}

Out of a total of 47 men and women who had undergone PCI, CABG and/or nonpharmacological treatment 3-7 weeks earlier at a general hospital in southwest Sweden, 24 patients (mean age 64 years [SD10.0], range 46-89 years) were randomised to the I-group and 23 patients (mean age 62 years [SD11.5], range 43-86 years) to the C-group. Sociodemography and self-reported medical history in the two groups is described in Table 1.

\section{Before intervention}

Before the intervention there were no differences between the I-group and the C-group regarding sleep quality, SE\%, sleep onset latency, sleep duration and nocturnal awakenings assessed by the USI, sleep diary and actigraphy (Table 3). However, there were significant differences between the groups in the SF-36. At baseline the patients in the I-group had more 
bodily pain $(p=0.03)$ and lower general health than the patients in the C-group $(p=0.006$, Table 3).

\section{Sleep and HRQoL outcome after intervention}

In the I-group, the individualised programme to promote self-care of the sleep-activity intervention appeared to be effective in improving patients' sleep quality, SE\% and decreased nocturnal awakenings as reported in the USI, median sleep quality, sleep duration and SE\% for 10 days as reported in the sleep diary as well as SE\% assessed with actigraphy recordings (Table 3). However, there was a tendency to improvement in sleep latency (sleep diary). The improvements that were identified in sleep diary and actigraphy for the I-group were not revealed to the C-group. Fragmentation index indicated that all patients had disrupted sleep that could be related to poor sleep whereas physical strain did not appear to be significant.

This study showed that the I-group had a statistically significant decrease of insomnia symptoms at 3-4 months follow-up compared to the C-group.

Eight of 24 patients (30\%, missing values 5) in the I-group had reported improved sleep in the sleep diary due to the CD-based relaxation programme (score $\geq 2=$ to some extent to very much).

At evaluation of the patients' set goals in the I-group, 18 patients (75\%) reported evaluated goals. Seven patients had accomplished all set goals (1-3 goals), seven partly and four did not achieve any of their goals.

In the I-group, improvements in HRQoL were seen in role-physical, vitality and social functioning, resulting in a significant improvement in mental component score $(\mathrm{p}<0.05)$. In the C-group, improvements were seen in physical functioning and vitality (Table 3). 
- Please insert Table 3 about here-

\section{Clinical significance}

At follow-up, a multiple stepwise regression analysis of sleep quality as perceived over the last 4 weeks and assessed using the USI explained 50.9\% of the variables sleep onset latency, SE\% at baseline (USI) and mean score for 10 days of sleep quality in the sleep diary ( $<0.0001$, Table 4). Belonging to the I-group or the C-group was not a statistically significant variable in the model.

- Please insert Table 4 about here- 


\section{DISCUSSION}

There is a large body of evidence showing that lifestyle modification nurse-based programmes effectively improve risk factors and related health behaviors, quality of life, morbidity, and mortality in patients with CAD (AHA 2010, Berra et al. 2011). No other study has been found that evaluates the effectiveness of an individualised programme to promote self-care in sleep-activity in patients with CAD following treatment.

The present study indicates that patients with CAD who had undergone PCI, CABG and/or were put on pharmacological treatment had statistically significantly improved their sleep quality and SE\%, and reduced nocturnal awakenings assessed with the USI. In addition, insomnia, which implies sleep-related complaints with non-restorative sleep, had also improved at 3-4 months follow-up. The C-group, who also received a brochure about stress and sleep, showed fewer results in the USI, with the exception for improved sleep quality and SE\%. Both groups reported quite bad sleep quality at baseline, while the C-group had the greatest improvement at follow-up compared to the I-group. Compared to the study by Johansson et al. (2011), which includes patients with CAD, Canadian Cardiovascular Society classes I and II, scheduled for coronary angiography, the patients in this study had lower SE\%, poorer sleep quality and shorter sleep duration at baseline. One explanation could be that other factors can reflect symptoms related to the patients' underlying diseases, pharmacological treatment or to sleep hygiene. Studies on non-pharmacological approaches in general practice show promising results, especially when the program is combined with training on sleep, sleep hygiene, stress management and relaxation, nutritional advice and practical training with the support of nurses and physiotherapists (Espie at al. 2007, Söderström 2007) Compared to the randomized cognitive behavior therapy study by Espie et al. (2007) on participants with insomnia in general practice, the patient in this study also had 
a significant improvement in SE\% at follow-up assessed by sleep diary. In addition, our results also showed a significant improvement in SE\% registered by actigraphy. However, SE\% was lower than recommended, i.e. an SE\% of at least 85\%. Sleep efficiency (SE\%) is an important variable measuring the amount of time in bed actually spent sleeping. In the present study, $37.5 \%$ of the patients in the I-group had shorter nocturnal sleep duration than the recommended 7-8 hours per night at baseline (Banks et al. 2007). Furthermore, an interesting result was that the I-group had increased their median sleep duration assessed by sleep diary for 60 minutes at the 3-4 month follow-up $(\mathrm{p}=0.04)$.

In this study, reported frequency of excessive daytime sleepiness (ESS) score $>10$ was lower than reported by Zhao et al. (2011) in patients with CAD under optimal medications treated with continuous positive airway pressure.

The patients in the I-group reported better sleep quality, longer sleep duration and had better SE\% in the sleep diary following an individualized intervention programme to promote selfcare of sleep-activity. Improved SE\% was also verified by the actigraphy recordings. It was interesting to see that the analysis of a 10-day diary showed statistically significantly more improvements in the I-group at the 3-4month follow-up. In contrast, the C-group did not show improvements in their sleep in the sleep diary. Cross et al. (2010) used a sleep diary and actigraphy for 14 days in patients with CAD compared to patients with an implantable cardioverter defibrillator. When we compared the CAD patients' mean values with our results, our patients had higher SE\% but shorter sleep duration assessed with actigraphy. In the sleep diary similar results were seen for SE\% compared with our follow-up results. Furthermore, the I-group had shorter sleep onset latency and longer sleep duration. Sleep duration was more than one hour longer than in the study by Cross et al. (2010). 
The present study showed that even if patients' sleep was substantially improved in response to interventions by a minor education and training programme, they did not become good sleepers with values corresponding to those with good sleep. Similar restrictions have been reported by Lacks and Morin (1992) following response to cognitive-behavior interventions in subjects with primary insomnia. However, patients' health needs to be considered in relation to what they can accomplish. Our reflection is that improved SE\% is not sufficient but that a subjective feeling of being rested by sleep is of importance.

Corresponding with other research (West et al. 2012), despite individual recommendations by a physiotherapist regarding physical activities and relaxation training combined with a CDbased relaxation programme, the patients in the I-group had not increased their physical activity at follow-up. Surprisingly, the C-group experienced better physical functioning in the SF-36 compared to the I-group at follow-up. One explanation could be that more individuals in the C-group were employed. However, research has shown that self-relaxation training effectively affects cognitive functions through improved sleep quality (Sun et al. 2013). The present study showed that sleep quality was also statistically significantly more improved in the I-group at follow-up. Our reflection is that improved sleep quality per se can promote next day exercise participation.

A recent study by Johansson et al. (2011) showed considerably lower score for HRQoL in several domains including physical functioning in CAD patients $(n=880)$ compared to patients in our study. One explanation could be that our participants were above average regarding physical activity and our sample was also very small. Weintraub (2008) showed that PCI was associated with greater improvement in physical functioning up to 24 months after treatment compared to medical treatment alone. Another explanation could be that several of the patients in our study had undergone PCI before inclusion (Table 1). This may also have influenced our results regarding physical functioning. Another study (Dueñas et al. 2011) of 
patients with CAD following treatment showed corresponding results with our study for several domains in HRQoL, especially among women at the 3-month follow-up. The patients in the I-group increased statistically significantly in role-physical, vitality and social functioning over time, similar to the women in the study by Dueñas et al. (2011).

Nurse-led programmes with education and follow-up for patients with heart failure have been shown to improve self-care and fewer days spent in hospital (McAlister et al. 2004).These management programmes have also been proven cost saving and effective in patients with CAD (Young et al. 2012) and in various populations (Huang et al. 2008, Chow \& Wong 2010). Other research findings support the need for a gender-specific and individualized targeted and tailored intervention to assist in symptom management and recovery from CABG (Zimmerman et al. 2007, 2011). This study demonstrates the importance of including assessment of sleep and sleeplessness behavior in daily clinical practice.

In conclusion, the majority of the patients in the current study followed the advice and tried to make a change to their situation, but a 3-4 month follow-up is too short for sufficient impact. The goal setting in the individualised self-care management programme was intended to empower the patients to actively participate in their own care, make informed choices about treatment and health care behaviors and engage in self-care with competence and selfefficacy.

It is important to take into account the additive effect of sleep variables as well as focus on the patients' individual perception of their sleep, related to the patient's context and own goals. In similar patient groups it has been shown that poor self-care may impair HRQoL and contribute to symptom burden and decreased functional capacity, but further research over 
time is needed (Grady 2008). There is a lack of knowledge about the management of these skills.

To reach a state of reflective, knowledgeable and sufficient self-care over time, the health care professionals have to give targeted education, engage and motivate the patient (Riegel et al. 2012), set individual realistic goals in relation to the individual's capabilities together with the patient in order to improve sleep and daytime functioning.

\section{STUDY LIMITATIONS}

There are some limitations in this study. First, despite significant outcomes, findings support the need for a study using a larger sample before further conclusions can be drawn. The patients were recruited from only one medical centre. The patients were followed-up 3-4 months after the individualised education programme, which is a quite short period. Therefore, a follow-up after one year is important. We did not control for patients taking part in other programmes. According to the calculated sample-size and power we did not retain 50 patients in each group despite the long inclusion period. However, a total of 940 sleep-wake cycles were objectively collected by actigraphy recordings, that is, 20 per patient, which is a strength in the study.

\section{CONCLUSION}

These findings indicate that an individualised education programme to promote self-care of sleep-activity including relaxation in patients with CAD supported by a nurse may improve sleep quality. However, a longitudinal study to promote self-care in sleep-activity should be performed using a larger sample and multiple sites with continuous follow-ups to determine whether any positive effects remain stable over time. 


\section{RELEVANCE TO CLINICAL PRACTICE}

Implementation of an individualised programme based on the patients' needs to promote selfcare in sleep-activity supported by a healthcare team and led by nurses is important in clinical practice and should be easy to use in daily clinical routines. To improve the management of patients with cardiovascular diseases, nurses need to pay more attention to sleep disturbances. It is also very important to monitor the success of treatment from the patients’ perspective. Evaluation of patients' sleep must be included in the European guidelines for cardiovascular disease prevention in clinical practice.

\section{CONFLICT OF INTEREST}

This was not an industry-supported study. No conflict of interest has been declared by the authors. 


\section{REFERENCES}

AHA (2010) American Heart Association Prevention Committee of the Council on

Cardiovascular Nursing. Interventions to promote physical activity and dietary lifestyle changes for cardiovascular risk factor reduction in adults: a scientific statement from the American Heart Association. Circulation 122, 406-441.

Ancoli-Israel S, Cole R, Alessi C, Chambers M, Moorcroft W \& Pollak CP (2003) The role of Actigraphy in the study of sleep and circadian rhythms. Sleep 26, 342-392.

Banks S \& Dinges D (2007) Behavioral and physiological consequences of sleep restriction. Journal of Clinical Sleep Medicine 3, 519-528.

Beiske KK, Kjelsberg FN, Ruud EA \& Stavem K (2009) Reliability and validity of a Norwegian version of the Epworth sleepiness scale. Sleep \& Breathing 13, 65-72.

Berra K, Houston Miller N \& Jennings C (2011) Nurse-based Models for Cardiovascular Disease prevention. From research to clinical practice. Journal of Cardiovascular Nursing 26, 46-55.

Blackwell T, Redline S, Ancoli-Israel S, Schneider JL, Surovec S, Johnson NL, Cauley JA \& Stone KL (2008) Comparison of sleep parameters from actigraphy and polysomnography in older women: The SOF study. Sleep 31, 283-291.

Borbély AA (1987) The S-Deficiency hypothesis of depression and the two-process model of sleep regulation. Pharmacopsychiatry 20, 23-7.

Borbély AA (1994) Sleep homeostasis and models of sleep regulation. In Principles and Practice of Sleep Medicine (Kryger MH, Roth T, Dement WC, eds.), W.B. Saunders Company, Philadelphia, $2^{\text {nd }}$ ed, pp. 309-320. 
Brink E, Alsén P, Herlitz J, Kjellgren K \& Cliffordson C (2012) General self-efficacy and health-related quality of life after myocardial infarction. Psychology, Health \& Medicine 17, 346-355.

Buysse DJ, Reynolds CF $3^{\text {rd }}$, Monk TH, Berman SR \& Kupfer DJ (1989) The Pittsburgh Sleep Quality Index: A new instrument for psychiatric practice and research. Journal of Psychiatric Research 28, 193-213.

Buysse DJ, Ancoli-Israel S, Edinger JD, Lichstein KL \& Morin CM (2006)

Recommendations for a standard research assessment of insomnia. Sleep 29, 1155-1173.

Cambridge Neurotechnology Ltd. (2001) Actiwatch Sleep Analysis. Version 1.09 ed.

Camntech Ltd (2007) The Actiwatch user manual. Version 7.2. Cambridge Neurotechnology Ltd, UK.

Cappuccio FP, Cooper D, D'Elia L, Strazzullo P \& Miller MA (2011) Sleep duration predicts cardiovascular outcomes: a systematic review and meta-analysis of prospective studies. European Heart Journal 32, 1484-1492.

Chow SKY \&Wong FKY (2010) Health-related quality of life in patients undergoing peritoneal dialysis: effects of a nurse-led case management programme. Journal of Advanced Nursing 66, 1780-1792.

Cross NJ, McCrae CS, Smith KM, Conti JB \& Sears SF (2010) Comparison of actigraphic and subjective measures of sleep in implantable cardioverter defibrillator and coronary artery disease patients. Clinical Cardiology 33, 753-759. 
Czeisler CA \& Buxton OM (2011) The human circadian timing system and sleep-wake regulation. In Kryger MH, Roth T, Dement WC, ed. 5th ed. Principles and practice of sleep medicine. Philadelphia: W.B. Saunders Company p. 402-419.

Dempster M \& Donnelly M (2000) Measuring the health related quality of life of people with ischaemic heart disease. Heart 83, 641-644.

Dueñas M, Ramirez C, Arana R \& Failde I (2011) Gender differences and determinants of health related quality of life in coronary patients: a follow-up study. BMC Cardiovascular Disorders 11:24. Published online 2011 May 27 Doi: 10.1186/1471-2261-11-24.

Dyregrov A (2006) Lilla sömnboken. Handbok för folk som vill sova bättre (in Swedish). Studentlitteratur, Lund.

Edéll-Gustafsson U (1999) Sleep, psychological symptoms and quality of life in patients undergoing coronary artery bypass grafting (Dissertation) Faculty of Health Sciences, Department of Medicine and Care, Division of Nursing Science, University of Linköping, Linköping and Faculty of Medicine, Department of Neuroscience, Uppsala University of Sleep Disorders Unit, University Hospital Uppsala; Sweden.

Edéll-Gustafsson UM (2002) Insufficient sleep, cognitive anxiety and health transition in men with coronary artery disease: a self-report and polysomnographic study. Journal of Advanced Nursing 37, 414-422.

Edéll-Gustafsson UM, Svanborg E \& Swahn E (2006) A gender perspective on sleeplessness behaviour, effects of sleep loss, and coping resources in patients with stable coronary artery disease. Heart and Lung 35, 75-89.

Espie CA, MacMahon KMA, Kelly HL, Broomfield NM, Douglas NJ, Engleman HM, Mckinstry B, Morin CM, Walker A \& Wilson P (2007) Randomized clinical effectiveness 
trial of nurse-administered small-group cognitive behavior therapy for persistent insomnia in general practice. Sleep 30, 574-584.

Field A (2009) Discovering statistics using SPSS, 3nd edn. Oriental Press, Dubai

Grady KL (2008) Self-care and quality of life outcomes in heart failure patients. Journal of Cardiovascular Nursing 23, 285-292.

Harvey AG, Stinson K, Whitaker KL, Moskovitz D \& Virk H (2008) The subjective meaning of sleep quality: A comparison of individuals with and without insomnia. Sleep 31, 383-393. Hetta J, Almqvist M, Ågren H, Hambert G, Liljenberg GB \& Roos BE (1985) Prevalence of sleep disturbances and related symptoms in a middle-aged Swedish population. In: Koella W, Ruther E, Schultz H. Editors. Sleep '84, Stuttgart: Gustaf Fisher Verlag, 373-76.

Hetta J, Mallon L, Bengtsson H, Smedje H \& Broman JE (1998) Polysomnographic vs. questionnaire data on difficulties falling asleep and total sleep time. Journal of Sleep Research 7 (2) 117, Abstract.

Hoevenaar-Blom MP, Spijkerman AM, Kromhout D, van den Berg JF \& Verschuren WM, (2011) Sleep duration and sleep quality in relation to 12-year cardiovascular disease incidence: the Morgen study. Sleep 34, 1487-1492.

Huang T, Li Y \& Wang C (2008) Individualized programme to promote self-care among older adults with asthma: randomized controlled trial. Journal of Advanced Nursing 65, 348358.

Jansson E \& Anderssen SA (2008) General recommendations on physical activity. In FYSS 2008 Fysisk aktivitet i sjukdomsprevention och sjukdomsbehandling (Physical activity in the 
prevention and treatment of disease) (Ståhle A ed.) Part I, chapter 2, p 38-46. Upplaga1:2 Elanders, Sweden.

Jay SM, Lamond N, Ferguson SA, Dorrian J, Jones CB \& Dawson D (2007) The characteristics of recovery sleep when recovery opportunity is restricted. Sleep 30, 353-360.

Johansson A, Windahl M, Svanborg E, Fredrichsen M, Swahn E, Yngman-Uhlin P \& EdéllGustafsson U (2007) Perceptions of how sleep is influenced by rest, activity and health in patients with coronary heart disease: a phenomenographical study. Scandinavian Journal of Caring Science 21, 467-475.

Johansson A, Svanborg E, Swahn E, Ejdebäck J, Tygesen H \& Edell-Gustafsson U (2011) Sleep, arousal and health-related quality of life in men and women with coronary artery disease. Journal of Clinical Nursing 20, 2787-2801.

Johns MW (1991) A new method for measuring daytime sleepiness: the Epworth sleepiness scale. Sleep 14, 540-545.

Johns M \& Hocking B (1997) Excessive daytime sleepiness. Daytime sleepiness and sleep habits of Australian workers. Sleep 20, 844-849.

Lacks P \& Morin CM (1992) Recent advances in the assessment and treatment of insomnia. Journal of Consulting and Clinical Psychology 60, 586-94.

LeBlanc M, Beaulieu-Bonneau S, Mérette C, Savard J, Ivers H \& Morin CM (2007) Pshycological and health-related quality of life factors associated with insomnia in a population-based sample. Journal of Psychosomatic Research 63, 157-166.

Lichstein KL, Stone KC, Donaldson J, Nau SD, Soeffing JP, Murray D, Lester KW \& Aguillard RN (2006) Actigraphy validation with insomnia. Sleep 29, 232-239. 
McAlister FA, Stewart S, Ferrua S \& McMurray JJ (2004) Multidisciplinary strategies for the management of heart failure patients at high risk for admission: a systematic review of randomized trials. Journal of the American College of Cardiology 44, 810-819.

Miller MA \& Cappuccio FP (2007) Inflammation, sleep, obesity and cardiovascular disease. Current Vascular Pharmacology 5, 93-102.

Moher D, Hopewell S, Schulz KF, Montori V, Gotzsche PC, Devereaux PJ, Elborne D, Egger M \& Altman DG (2010) CONSORT 2010 Explanation and Elaboration: updated guidelines for reporting parallel group randomised trials. Journal of Clinical Epidemiology 63, e1- e37. Morin CM \& Espie CA (2004) INSOMNIA - A Clinical Guide to Assessment and Treatment. Springer, New York, NY.

Morin CM, LeBlanc M, Daley M, Gregoire JP \& Mérette C (2006) Epidemiology of insomnia: Prevalence, self-help treatments, consultations, and determinants of help-seeking behaviors. Sleep Medicine 7, 123-130.

Mullington JM, Haack M, Toth M, Serrador JM \& Meier-Ewert HK (2009) Cardiovascular, inflammatory, and metabolic consequences of sleep deprivation. Progress in Cardiovasular Diseases 51, 294-302.

Orem DE (2001) Nursing: Concepts of practice, 6th ed. St. Louis, Missouri: MO Mosby. Polit DE \& Beck CT (2008) Nursing Research Generating and Assessing Evidence for Nursing Practice $8^{\text {th }}$ ed Lippincott Williams \& Wilkins, Philadelphia.

Pörn I (1993) Health and adaptedness. Theoretical Medicine 14, 295-303.

Riegel B, Jaarsma T \& Strömberg A (2012) A middle-range theory of self-care of chronic illness. Advances in Nursing Science 35, 194-204. 
Spindler H \& Pedersen SS (2005) Posttraumatic stress disorder in the wake of heart disease:

prevalence, risk factors, and future research directions. Psychosomatic Medicine 67, 715-723.

Sullivan M, Karlsson J \& Taft C (2002) SF-36 Hälsoenkät: Svensk manual och

tolkningsguide (Swedish Manual and Interpretation Guide). 2nd ed. Gothenburg: Sahlgrenska University Hospital, Sweden

Sun J, Kang J, Wang P \& Zeng H (2013) Self-relaxation training can improve sleep quality and cognitive functions in the older: a one-year randomised controlled trial. Journal of Clinical Nursing 22, 1270-1280.

Söderström M. Sömn, sov bättre med kognitiv beteendeterapi (in English: Sleep, sleep better with cognitive behavioral therapy). Stockholm: Viva förlag; 2007.

Thernfrid C (2003) Sömn och stress (in English: Sleep and stress). Sanofi Aventis, SanofiSynthelabo, Bromma.

Ustinov Y, Lichstein KL, Wal GS, Taylor DJ, Riedel BW \& Bush AJ (2010) Association between report of insomnia and daytime functioning. Sleep Medicine 11, 65-68.

Vallièrs A \& Morin CM (2003) Actigraphy in the assessment of Insomnia. Sleep 26, 902-906.

Van de Water ATM, Holmes A \& Hurley DA (2011) Objective measurements of sleep for non-laboratory settings as alternatives to polysomnography - a systematic review. Journal of Sleep Research 20, 183-200.

Weintraub WS, Spertus JA, Kolm P, Maron DJ, Zhang Z, Jurkovitz C \& Zhang W, COURAGE Trial Research Group, Mancini GB (2008) Effect of PCI on quality of life in patients with stable coronary disease. The New England journal of medicine 359, 677-687. 
West RR, Jones DA \& Henderson AH (2012) Rehabilitation after myocardial infarction trial (RAMIT): multi-centre randomized controlled trial of comprehensive cardiac rehabilitation in patients following acute myocardial infarction. Heart 98, 637-644.

WMA (2008) World Medical Association Declaration of Helsinki. Ethical Principles for Medical Research Involving Human Subjects. Available at:

http://www.wma.net/en/30publications/10policies/b3/index.html (assessed 17 April 2013).

Young L, Zimmerman L, Pozehl B, Barnason S \& Wang H (2012) Cost-effectiveness of a symptom management intervention: improving physical activity in older women following coronary artery bypass surgery. Nursing economics 30, 94-103.

Zhao Q, Liu Z, Luo Q, Zhao Z, Zhang H \& Wang Y (2011) Effects of continuous positive airway pressure on blood pressure and daytime sleepiness in obstructive heart diseases under optimal medications. Sleep \& Breathing 16, 341-347.

Zimmerman L, Barnason S, Schulz P, Nieveen J, Miller C, Hertzog M, Rasmussen D \& Tu C (2007) The effects of a symptom management intervention on symptom evaluation, physical functioning, and physical activity for women after coronary artery bypass surgery. Journal of Cardiovascular Nursing 22, 493-500.

Zimmerman L, Barnason S, Young L, Tu C, Schulz P \& Abbott AA (2010) Symptom profiles of coronary artery bypass surgery patients at risk for poor functioning outcomes. Journal of Cardiovascular Nursing 25, 292-300.

Zimmerman L, Barnason S, Hertzog M, Young L, Nieven J, Schulz P \&Tu C (2011) Gender differences in recovery outcomes after an early recovery symptom management intervention. Heart \& Lung 40, 429-439. 
Assessed for eligibility $(\mathrm{n}=71)$

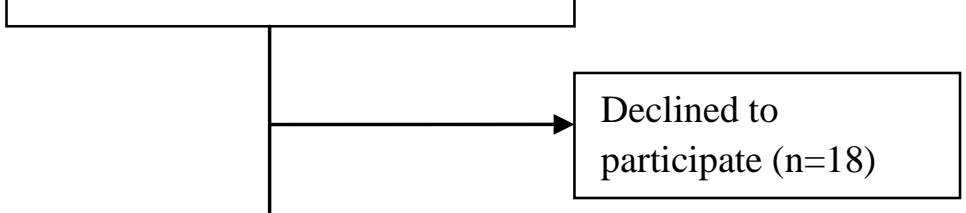

을

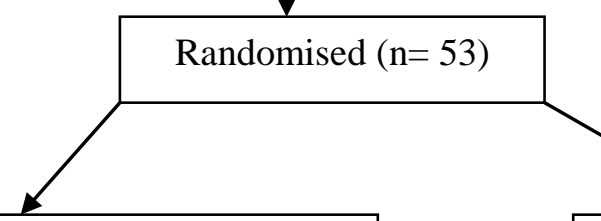

Allocated to intervention group $(\mathrm{n}=27)$

Received allocated intervention $(\mathrm{n}=26)$

Did not receive allocated intervention:

Excluded due to malignancy $(\mathrm{n}=1)$

Allocated to control group $(\mathrm{n}=26)$

Received allocated control $(\mathrm{n}=24)$

Did not receive allocated control:

Declined further participation $(n=2)$
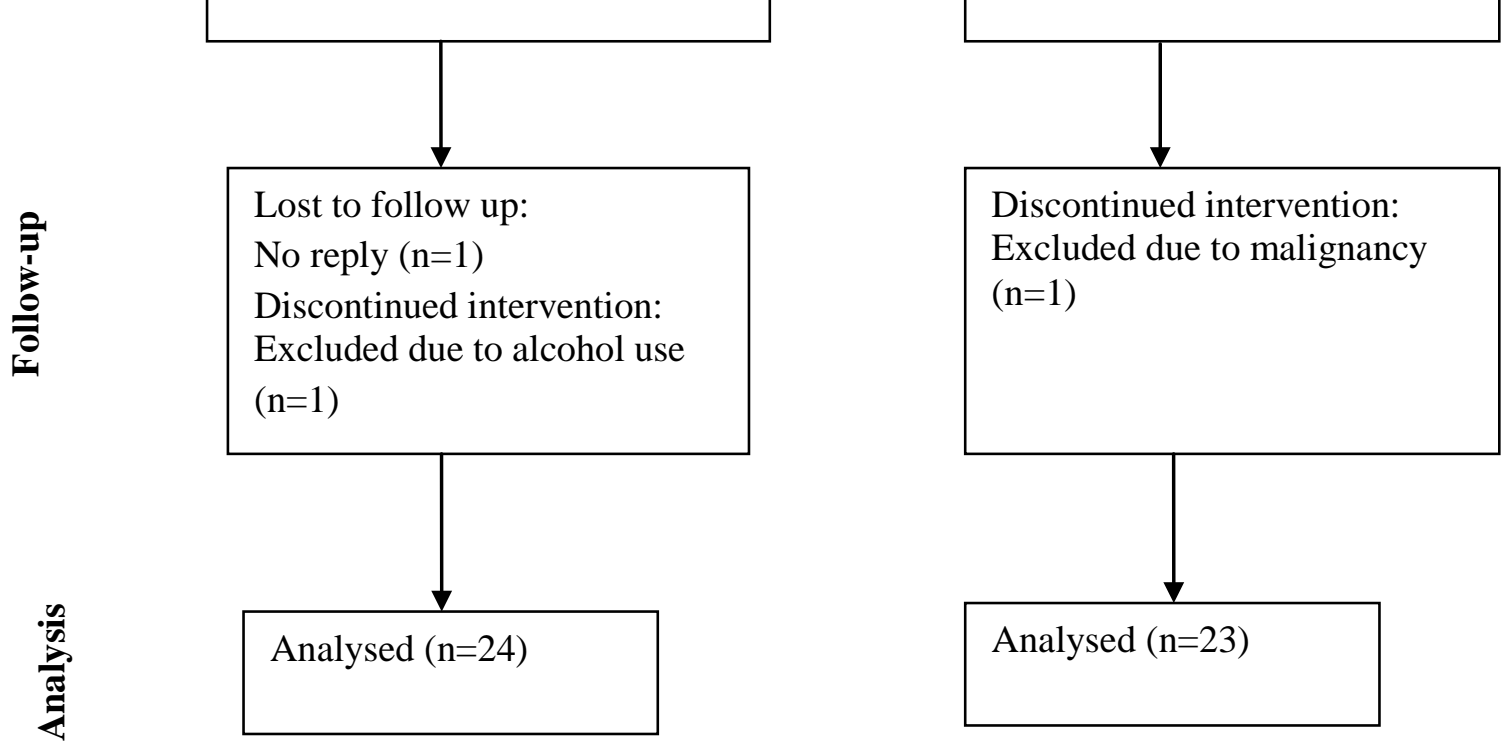

Figure 1. 
Figure 2. The flow for the time points of intervention and data collection.

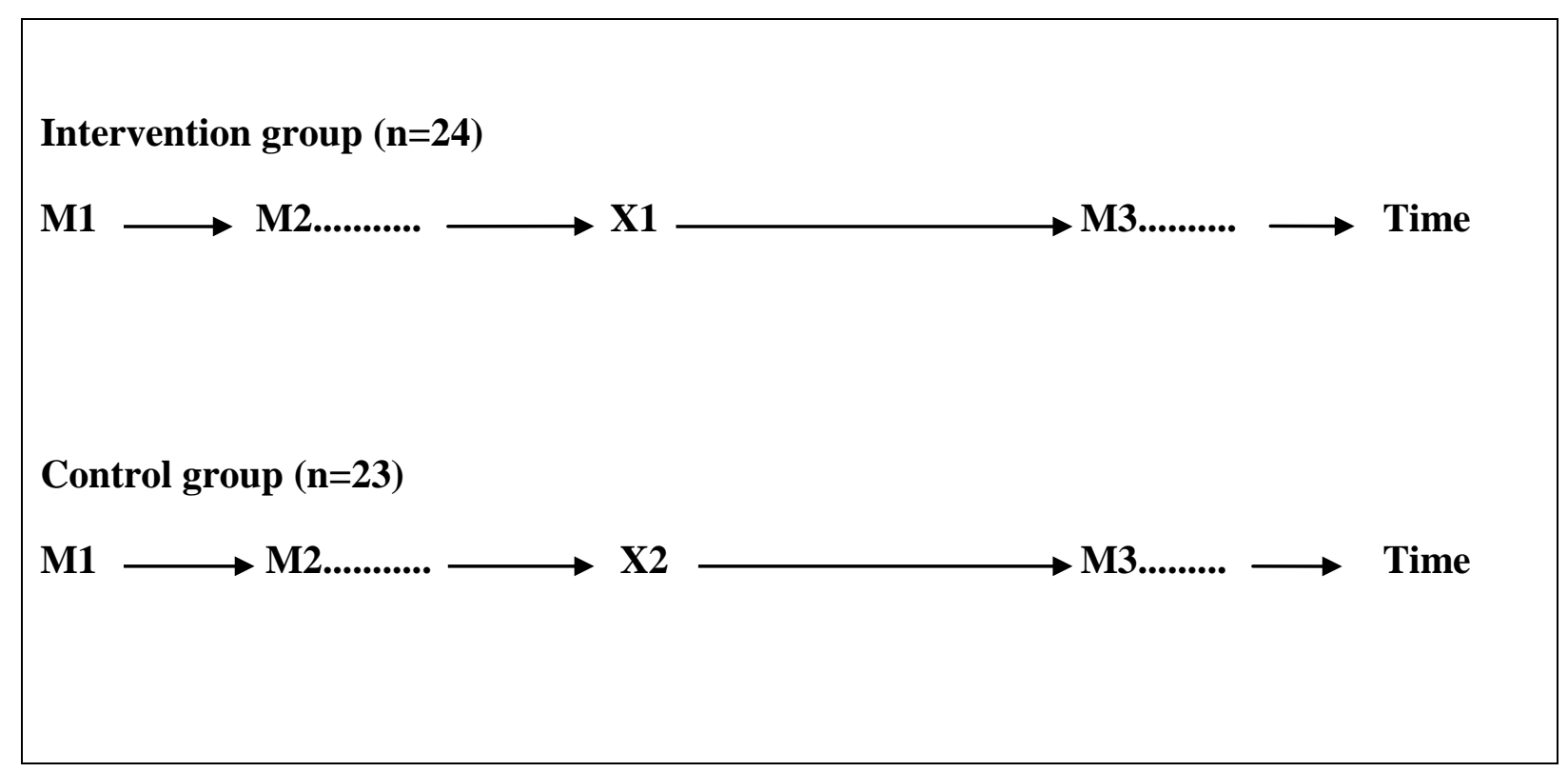


Legends

Figure 1. Flowchart of the participants’ progress through the trial phase.

Figure 2. The flow for the time points of intervention and data collection.

M1= Answering questionnaires at baseline. Time between $\mathbf{M 1}$ to M2 about 2 weeks. M2= Actigraphy registration with sleep diary for 10 consecutive 24-hour periods, $\mathbf{X 1}=$ Visit at the outpatient clinic after actigraphy registration was performed. An individualized programme to promote self-care of sleep-activity also including a relaxation programme and a sleep brochure. $\mathbf{X 2}=$ A sleep brochure was sent to the participants. M3= Evaluations 3-4 months after $\mathrm{X} 1$ or $\mathrm{X} 2$ by answering questionnaires and actigraphy registration with sleep diary for 10 consecutive 24-hour periods. The individualized programme did not belong to the routine care. No patient was excluded from the routine health care. 
Table 1. Socio-demography and self-reported medical history at baseline $(n=47)$.

\begin{tabular}{|c|c|c|c|}
\hline & $\begin{array}{l}\text { Intervention group } \\
\mathrm{n}=24\end{array}$ & $\begin{array}{l}\text { Control group } \\
n=23\end{array}$ & P-values \\
\hline & n (\%) & n (\%) & \\
\hline Women/Men & $10(41.7) / 14(58.3)$ & $6(27.3) / 17(73.9)$ & 0.26 \\
\hline Age mean (SD) & $64(10.0)$ & $62(11.5)$ & 0.35 \\
\hline Married/cohabiting & $20(83.3)$ & $21(91.3)$ & 0.41 \\
\hline Employed & $10(41.7)$ & $16(69.6)$ & 0.05 \\
\hline
\end{tabular}

\section{Self-reported disease ${ }^{a}$}

$\begin{array}{lccc}\text { Hypertension } & 16(66.7) & 13(56.5) & 0.47 \\ \text { Diabetes } & 3(12.5) & 1(4.3) & 0.61 \\ \text { Joint disorder } & 9(37.5) & 7(30.4) & 0.61\end{array}$


Muscular pain

Gastrointestinal problems

Previous myocardial infarction

Snoring $^{\mathrm{b}}$

Sleep apnoea ${ }^{\mathrm{b}}$

Body Mass Index ${ }^{\mathrm{c}}\left(\mathrm{kg} / \mathrm{m}^{2}\right)$

Self-reported preintervention

Coronary angiography

PCI

CABG

$$
4 \text { (16.7) }
$$

$8(34.8)$

21(87.5)

$11(47.8)^{d}$

$6(27.3)^{\mathrm{e}}$

$28(21-39)$

$24(100)$

20 (86.9)

11 (45.8)

$5(20.8)$
$7(30.4)$

0.32

7 (30.4)

0.75

$20(87.0)$

0.95

0.23

0.92

$6(28.6)^{\mathrm{e}}$

0.56

${ }^{\mathrm{a}}$ One patient can have more than one reported disease. ${ }^{\mathrm{b}}$ Confirmed by a bedfellow and rated 1-2 nights/week, (occasionally) to every or almost every night (very often). ${ }^{\mathrm{c}}$ Mean value (range). ${ }^{\mathrm{d}} 1$ missing value, ${ }^{\mathrm{e}} 2$ missing values. 
Table 2. Descriptions of measured actigraphy (Model AW-L, Cambridge Neurotechnology Ltd, UK) and sleep diary variables.

$\begin{array}{lll}\text { Variables } & \text { Description }\end{array}$

Sleep variables

Bedtime, nocturnal awakenings, wake time during the night,

morning awakening time, get up time, sleep duration and daytime napping.

Sleep latency

The latency before sleep onset following bedtime.

Sleep quality ${ }^{\mathrm{a}}$

Sleep efficiency

(SE\%) Ratio of actual sleep time divided by time in bed multiplied by 100 .

Fragmentation index ${ }^{\mathrm{b}}$ (FI) The addition of Percentage Minutes Moving and Percentage Immobility.

This is used as an indicator of disrupted and restless sleep.
Minutes

1 (well) - 5 (badly)

Acceptable value $\geq 85 \%$

$<20=$ good sleep, $>50=$ poor sleep

${ }^{\mathrm{a}}$ Registered only by sleep diary, ${ }^{\mathrm{b}}$ Registered only by actigraphy. 
Table 3. Comparisons of sleep between and within the intervention group and the control group assessed by the Uppsala Sleep Inventory (USI) the last 4 weeks, sleep diary and actigraphy recordings for 10 consecutive days, daytime sleepiness by the Epworth Sleepiness scale (ESS), health-related quality of life (HRQoL) assessed by SF-36 at baseline and at follow-up after 3-4 months.

\begin{tabular}{|c|c|c|c|c|c|c|}
\hline & \multicolumn{2}{|l|}{ Baseline (M1) } & \multicolumn{2}{|l|}{ Follow-up (M3) } & \multicolumn{2}{|l|}{ P-value $^{\dagger}$} \\
\hline & Intervention group & Control group & Intervention group & Control group & $\begin{array}{l}\text { Intervention } \\
\text { group }\end{array}$ & Control \\
\hline & $n=24$ & $n=23$ & $n=24$ & $n=23$ & M1 vs M3 & M1 vs M3 \\
\hline & $\operatorname{Md}\left(\mathrm{Q}_{1}-\mathrm{Q}_{3}\right)$ & $\operatorname{Md}\left(\mathrm{Q}_{1}-\mathrm{Q}_{3}\right)$ & $\operatorname{Md}\left(\mathrm{Q}_{1}-\mathrm{Q}_{3}\right)$ & $\operatorname{Md}\left(\mathrm{Q}_{1}-\mathrm{Q}_{3}\right)$ & & \\
\hline \multicolumn{7}{|l|}{ Uppsala Sleep Inventory (USI) } \\
\hline Sleep quality 1 (good) - 5 (bad) & $4(3-4)$ & $4(3-4)$ & $3(2-3)$ & $2(2-3)$ & 0.005 & 0.01 \\
\hline Sleep duration (hour:min) & $6: 0(5: 0-6: 30)$ & $6: 0(5.0-6.30)$ & $6: 30(6: 0-7: 0)$ & $6: 0(6: 0-7: 30)$ & 0.10 & 0.05 \\
\hline Sleep onset latency (min) & $30(11-56)$ & $30(10-60)$ & $25(10-60)$ & $20(10-30)$ & 0.82 & 0.48 \\
\hline Nocturnal awakening (freq) & $3(2-3)$ & $3(2-3)$ & $1.5(1-2)$ & $3(2-3)^{*}$ & 0.005 & 0.32 \\
\hline Sleep efficiency (\%) & $65(53-77)$ & $68(58-75)$ & $79(64-86)$ & $78(70-86)$ & 0.008 & 0.004 \\
\hline Sleep efficiency $<85 \%$ n $(\%)^{\ddagger}$ & $23(95.8)$ & $21(91.3)$ & $17(70.8)$ & $15(65.2)$ & $0.03^{\S}$ & $0.03^{\S}$ \\
\hline Napping n (\%) & $15(62.5)$ & $16(69.6)$ & $13(54.2)$ & 17 (73.9) & $0.69^{\S}$ & $1.00^{\S}$ \\
\hline Insomnia & $4(3-4)$ & $3(3-4)$ & $3(3-4)$ & $3(3-3)$ & 0.02 & 0.10 \\
\hline ESS >10 score, n (\%) & $6(25)$ & $8(34.8)$ & $5(20.8)$ & $7(30.4)$ & $1.00^{\S}$ & $1.00^{\S}$ \\
\hline \multicolumn{7}{|l|}{ Sleep Diary } \\
\hline Sleep quality ${ }^{\dagger \dagger} 1$ (good) - 5(bad) & $3(2-3)$ & $3(2-3)$ & $2(2-2.5)$ & $3(2-3)^{*}$ & 0.009 & 0.97 \\
\hline Sleep duration ${ }^{\dagger \dagger}$ (hour) & $6: 0(6: 0-7: 0)$ & $7: 0(6: 0-8: 0)$ & $7: 0(6: 0-8: 0)$ & $7: 0(6: 0-8: 0)$ & 0.04 & 0.21 \\
\hline Sleep latency ${ }^{\dagger \dagger}$ (min) & $35(21-62)$ & $26(13-38)$ & $25(16-34)$ & $40(16-58)$ & 0.07 & 0.78 \\
\hline Nocturnal awakening $^{\dagger \dagger}$ & $2(1-2)$ & $2(1-3)$ & $1(1-2)$ & $2(1-3)$ & 0.31 & 0.69 \\
\hline Sleep efficiency ${ }^{\ddagger,+\dagger}$ & $73(66-81)$ & $83(62-87)$ & $83(74-90)$ & $84(73-87)$ & 0.005 & 0.33 \\
\hline Napping n (\%) & $17(70.8)$ & $17(73.9)$ & $10(45)^{\ddagger \ddagger}$ & $12(57)^{\ddagger \ddagger}$ & $0.04^{\S}$ & $0.12^{\S}$ \\
\hline
\end{tabular}




\section{Actigraphy recordings}

Sleep duration (hour:min) ${ }^{\dagger \dagger}$

Sleep efficiency ${ }^{\ddagger,+\dagger}$ (\%)

Fragmentation index ${ }^{\dagger+, \S \S}$

$$
\begin{aligned}
& 6: 0(5: 30-6: 0) \\
& 71(63-75) \\
& 37.0(26.6-47.1)
\end{aligned}
$$

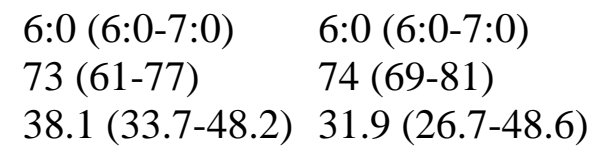

\section{SF-36}

Physical functioning

Role-physical

$75(60-89)$
$25(0-50)$
$41(22-52)$
$45(35-60)$
$45(30-55)$
$62(50-87)$
$67(33-100)$
$64(52-76)$
$39(29-43)$
$46(28-52)$

$\begin{array}{ll}72(59-85) & 83(60-90) \\ 12(0-81) & 75(25-100) \\ 51(41-84)^{*} & 42(41-61) \\ 60(49-78)^{* *} & 52(30-72) \\ 40(35-57) & 60(30-70) \\ 75(62-87) & 87(75-100) \\ 83(0-100) & 100(33-100) \\ 68(63-81) & 72(60-84) \\ 37(30-50) & 42(32-50) \\ 42(34-51) & 52(41-54)\end{array}$

$80(67-95)-0.274$

$50(0-100) \quad 0.038$

$74(41-100)^{*} \quad 0.155$

$60(45-72) \quad 0.399$

$55(44-66) \quad 0.013$

$81(62-100) \quad 0.008$

$100(33-100) \quad 0.094$

$74(67-84) \quad 0.128$

$43(33-54) \quad 0.088$

$48(40-53) \quad 0.036$

0.006

0.129

0.125

0.354

0.010

0.098

0.180

0.114

0.527

Mental component score

${ }^{\dagger}$ the p-value of within groups pre- and post-test, Wilcoxon signed-rank test. ${ }^{\ddagger}(\mathrm{SE} \%)=$ the ratio of nocturnal sleep duration and time in bed in

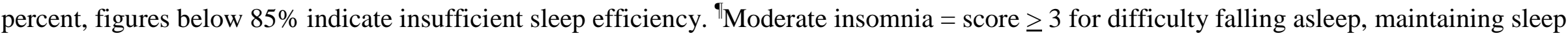
and early morning awakening and/or > 30 min sleep onset latency, > 30 min nocturnal awakening, early awakening > 30 min before desired morning awakening, and/or nocturnal sleep duration $<6 \mathrm{hr}$ combined with at least one daytime symptom of sleep loss in the USI. Severe insomnia score $\geq 4$ and/or combined with any of the above items. ${ }^{\dagger \dagger}$ Mean value for 10 days. ${ }^{\S \S}$ Fragmentation index indicates restless sleep; summary of percentage of minutes moving and percentage of immobility, bad sleep ( $>50)$ and very good sleep $(<20) .{ }^{\ddagger}$ Two missing values. ${ }^{\S}$ McNemar's test. ${ }^{*} \mathrm{p}<0.05,{ }^{* *} \mathrm{p}<0.01$, the $\mathrm{p}$-value of comparison between groups, Mann-Whitney test. 
Table 4. Multiple stepwise regression analysis of sleep quality (at follow-up) assessed by the Uppsala Sleep Inventory (USI) scored on a 5-grade scale, from good [score 1] to bad [score 5], $(n=47)$.

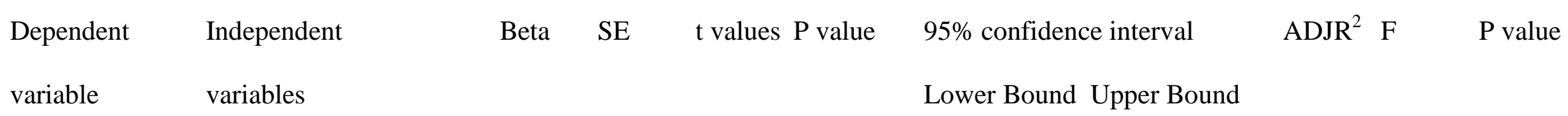

$\begin{array}{rlrlllll}\text { Sleep quality }^{\dagger} & \text { Sleep onset latency }^{\dagger} & .376 & .003 & 3.065 & 0.004 & .003 & .015 \\ & \text { Sleep efficiency }^{\Uparrow} & -.383 & .008 & -3.183 & 0.003 & -.042 & -.009 \\ & \text { Sleep quality }^{\ddagger} & .249 & .182 & 2.155 & 0.038 & .023 & .761\end{array}$

${ }^{\dagger}$ measured by USI, as perceived during the last 4 weeks at follow-up. ${ }^{\top}$ Measured by USI at baseline, SE\%= the ratio of nocturnal sleep duration and time in bed expressed in percent, figures below $85 \%$ indicate insufficient sleep efficiency. ${ }^{\ddagger}$ Measured by sleep diary, mean value for ten days at followup. 